\title{
Early Trompe-l'oeil Effects in the Last Supper Depictions by Domenico Ghirlandaio
}

\author{
Sylvie Duvernoy ${ }^{1}$ (D) Giampiero Mele $^{2}$
}

\begin{abstract}
The many frescoes showing the Last Supper of Jesus and the Apostles painted in Florence in the Renaissance have already been studied at length by art historians. However they have never been analyzed and investigated from the point of view of the relationship between art and perspective science, and the relationship between the shape of the room that they decorate and the shape of the space that they depict. Perspective science was being mathematically codified and put into written words by Piero della Francesca in the very days in which Domenico Ghirlandaio painted two frescoes in the convents of San Marco and Ognissanti. We can thus consider Ghirlandaio's paintings as being pioneering art works that mark a turning point in this artistic genre, and we will try to understand how and to what extent he mastered the trompe l'oeil effects that he produced.
\end{abstract}

Keywords Ghirlandaio · Last supper · Renaissance fresco · Perspective science

\section{Introduction}

Depictions of the Last Supper in Christian art have been undertaken by artistic masters for centuries and the Florentine Renaissance is particularly rich in such art works. The Last Supper was traditionally painted on the walls of the refectories of the convents, and was often coupled with other biblical scenes, such as the

Sylvie Duvernoy

sylvie.duvernoy@polimi.it; sylvie.duvernoy@yahoo.it

Giampiero Mele

giampiero.mele@uniecampus.it; giampiero.mele@polimi.it

1 Politecnico di Milano, Milan, Italy

2 Università e-campus Novedrate, Milan, Italy 
crucifixion. The comparison of the many frescoes that are found in the city and its surroundings shows that the question of architectural perspective and the progress in geometry and theoretical science had a strong impact on the evolution of the depiction of this scene.

In the second half of the fifteenth century, Domenico Ghirlandaio (1449-1494) painted three frescoes showing the Last Supper of Jesus and the Apostles, in three different Florentine convents. The first one, dated 1476, stands in the refectory of the Badia a Passignano, outside Florence. The other two, which are the subject of the analysis of this paper, are in the city of Florence: one in the Convent of San Marco and one in the Convent of Ognissanti. Scholars in art history are unsure about the chronological order of the two later paintings. They were both painted in a time span of two or three years, and they share many similar features. Until a few years ago Ognissanti was considered to be the first and San Marco the second, but recent studies by Italian researchers tend to prove that the contrary might be true (Acidini Luchinat and Proto Pisani 1997). Following this new interpretation, San Marco is now dated 1480 and Ognissanti 1482.

The Passignano fresco shows a scene in traditional style, in which the medieval influence is still very strong. Jesus and the Apostles are seated in a sort of open porch closed by a balustrade, with a flat decorated ceiling, whose entrance door is nowhere to be seen. This setting is very similar, for instance, to the one that Andrea del Castagno had painted in the Convent of Sant'Apollonia in 1447, some twenty years before (Fig. 1).

In Sant'Apollonia the Supper takes place in a kind of free-standing shelter, a sort of covered stage that seems to have been built especially for the ceremony. Instead,

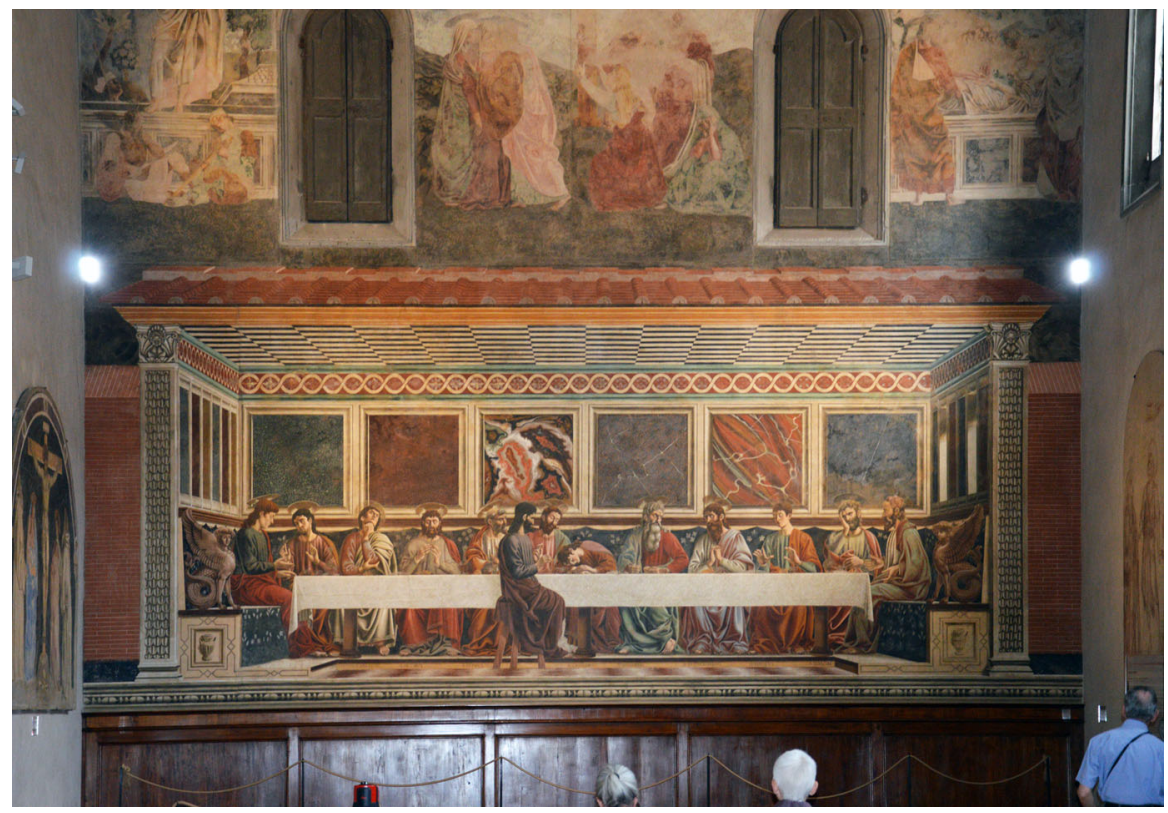

Fig. 1 Andrea del Castagno. Last Supper in Sant'Apollonia, Florence, 1447. Photo: authors 
in San Marco, Ghirlandaio painted the scene in a very innovative way. For the very first time the representation of the Last Supper covers the full wall on which it is painted: no other biblical scene is there to enhance the dramatic atmosphere. For the first time, the mensa around which Jesus and the Apostles are seated is shaped as a $\mathrm{C}$, with eight persons (including Jesus) seated behind the long middle side, four other (two + two) seated behind the short sides of the C, and Judas alone, on the other side of the mensa, facing Jesus. For the first time, the vaulted space in which the meal is taking place has architectural features recalling those of the room to which the painted wall belongs. Also, the sitting bench with its high back, having the same C-shape as the mensa, acts as a continuation of the traditional furnishing of a refectory. In the convent of Ognissanti Ghirlandaio repeated the same setting, composing his fresco in nearly the same way.

All these novelties show that the intention to create a visual continuity between the real space of the refectory and the painted virtual space is indeed the true innovation of these art works. It seems that in the very few years that passed between the Passignano painting and the later ones, Ghirlandaio had either enlarged his theoretical knowledge and his artistic talent, or had been under the influence of some learned colleague who suggested that he approach the depiction of virtual space in perspective from a completely different standpoint. Those were the years in which Piero della Francesca (1416-1492) was finishing his treatise entitled De prospectiva pingendi (1984), believed to have been completed in $1482 .{ }^{1}$ Painters of all Italy must have been aware of the scientific progress in perspective, and Piero himself had already opened the way to innovative applications in painting with the Flagellation of Christ (1460 ca. -before 1475) and the Pala di Brera (1472).

\section{Goal and Methodology}

Our study was intended to investigate in depth the relationship between the real space of the refectories of San Marco and Ognissanti and the virtual space depicted on their walls. We wished to understand how and to what extent the effect of visual continuity was scientifically controlled, thanks to the accurate perspective construction of a virtual space whose size and shape had been purposely defined.

\section{Data Collection}

The first step of the research was to acquire reliable numerical data regarding both the refectories and the paintings. In San Marco first and then in Ognissanti, we measured the volume and shape of the room with an electronic 3D disto-laser,

\footnotetext{
${ }^{1}$ In the dedication of his book Libellus de Quinque Corporibus to the duke Guidobaldo da Montefeltro, Piero recalls that he had written the De prospectiva pingendi several years before. Giusta Nicco-Fasola asserts that he may be saying that he offered it to Guidobaldo's father, the Duke Federico da Montefeltro, which means that the De prospectiva was finished in 1482, the year of Federico's death (Piero della Francesco 1984: 46). The first historical citation of the De prospectiva pingendi is by Luca Pacioli, who mentions it in his Summa de arithmetica, geometrica, proportioni et proportionalita, which was written in 1490 while Piero was still alive.
} 
carrying out three virtual sections: one horizontal and two vertical (one longitudinal and one transversal). Simultaneously, we made a thorough photographical survey of the refectory and processed the pictures with an appropriate software for 3D reconstruction from multiple images, thus obtaining an accurate $3 \mathrm{D}$ digital model of the room. The model could be processed both as a point cloud and meshed surfaces. Coupling the model with the measurements allowed us to scale it and consequently retrieve some additional dimensions when necessary. With the disto-laser we also measured the position of some relevant points on the painting such as the vertices of the decorative grid of the floor, the base of the background arches, the corners of the mensa, etc. This made it possible to produce a digital orthophoto of the fresco, scaled to its true dimension, that we could eventually map on the 3D model and/or analyse separately.

\section{Data Interpretation}

Analysing and understanding such murals is a tricky process. The painter may have built his perspective after having drawn some quick sketch of the plan of the architectural scene... or may have not. Because of its overall simplicity, the spatial design of the scene may also have been drawn directly in perspective since the construction of the pavement grid would have been enough to construct the full view of the whole virtual space, and add the figures, birds, and objects later on. If any preparatory sketches in plan or in elevation ever existed, they are long lost, and therefore we have to work with the sole image of the painting. Further, since a single drawing is never enough to describe unmistakably and thoroughly an architectural space or volume, the analysis of the shape of the virtual space depicted by a single perspective view, has to rely on assumptions regarding the shape itself: are the decorative patterns on the floor meant to be perfect squares? Are the vaults on the painting those of a space which is square in plan? Those assumptions have to be carefully weighed, and evaluated with the spirit of the Renaissance artist at the dawn of perspective science.

\section{San Marco}

The Last Supper depicted in San Marco covers a wall on the short side of a rectangular room (Fig. 2). The wall is $7.82 \mathrm{~m}$ wide, and its maximum height (at the top of the vault lunette) is $5.96 \mathrm{~m}$. Expressed in Florentine braccia-the measure unit of that time, equal to $0.583 \mathrm{~m}$-it would be $13-1 / 2$ by $10-1 / 4 \mathrm{circa}^{2}$ The fresco bottom is at a height of exactly three braccia from the floor $(1.75 \mathrm{~m}$.), and shows Jesus and the Apostles seated in a loggia, covered by two cross vaults, whose short sides are closed by a wall with a window, while the long side opens towards a garden which has been interpreted as the garden of Eden. The furniture: the C-shaped mensa and the bench on which Jesus and the Apostles seat, are arranged in

\footnotetext{
2 Florentine braccio $=0.583 \mathrm{~m}$, and the subdivisions for braccia were: 2 palmi $=20$ soldi $=60$ quattrini $=240$ denari $=2880$ punti.
} 


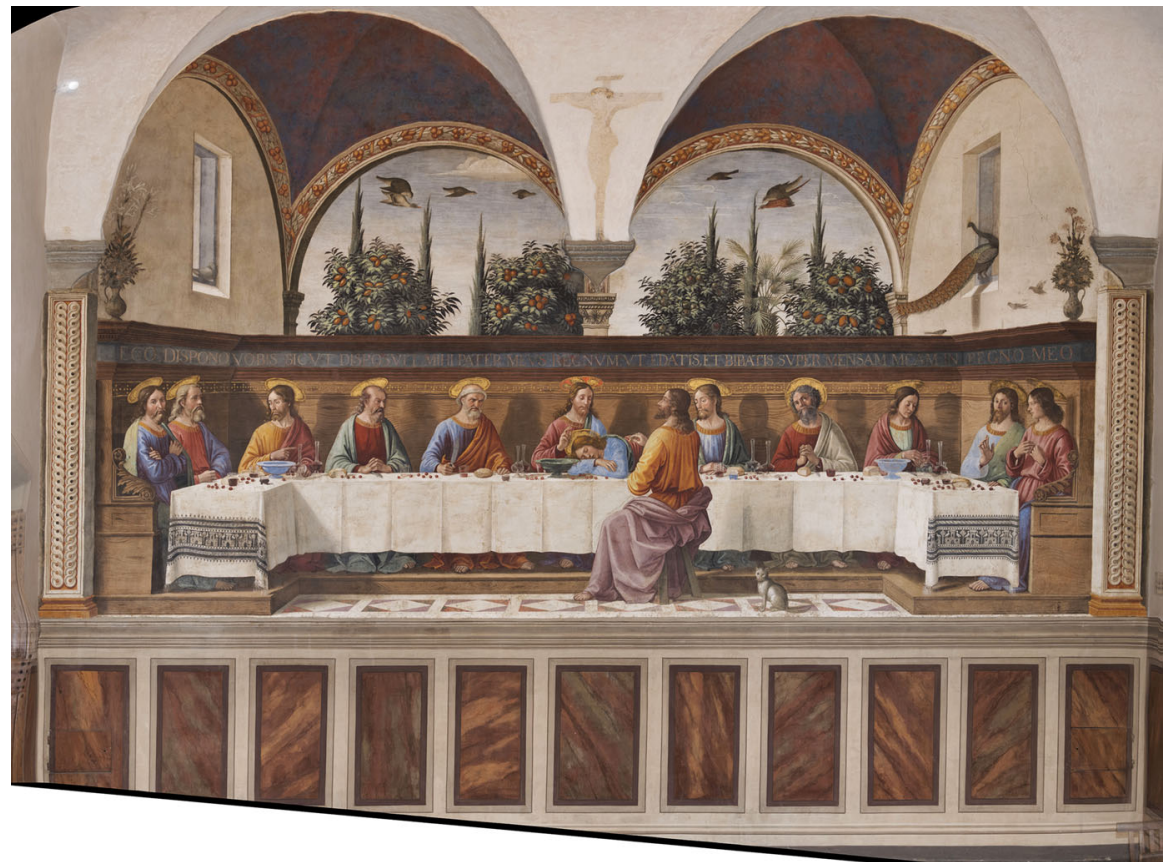

Fig. 2 Ghirlandaio. Last Supper in the convent of San Marco, Florence, 1480. Photo: authors

the first half of the loggia, occupying its full length but a little less than half of its available depth. The other half of the covered space is supposedly empty, acting as a transition space to the garden behind.

\section{First Hypothesis}

For our first investigation we assume that the decoration of the floor in the first ground is designed on the basis of a grid of perfect squares (Figs. 3, 4, 5, 6). Squared patterns are indeed recurrent on the floors of Renaissance Italian paintings. We could mention many famous examples, from the paintings by Piero della Francesca to those by Perugino, as well as the three renowned representations of the Ideal City (the panels of Urbino, Baltimore and Berlin). The exact representation of a horizontal square grid is the first step for any construction of perspective drawing. The rule for its delineation was in fact the very first rule to be defined, making the further progress in perspective science possible. All perspective treatises, from Alberti on, start with the explanation of this first step, which allows the artist to measure the apparent depth of the space, and therefore control the dimensions and the positions of the various elements included in the scene. It seems thus legitimate to assume that the coloured floor decoration (completed in the painting phase subsequent to the drawing phase) would predictably follow the initial construction grid, enhancing the classical proportions that any viewer would easily recognize, acting as a guide to the "reading" and understanding of the painted space. 


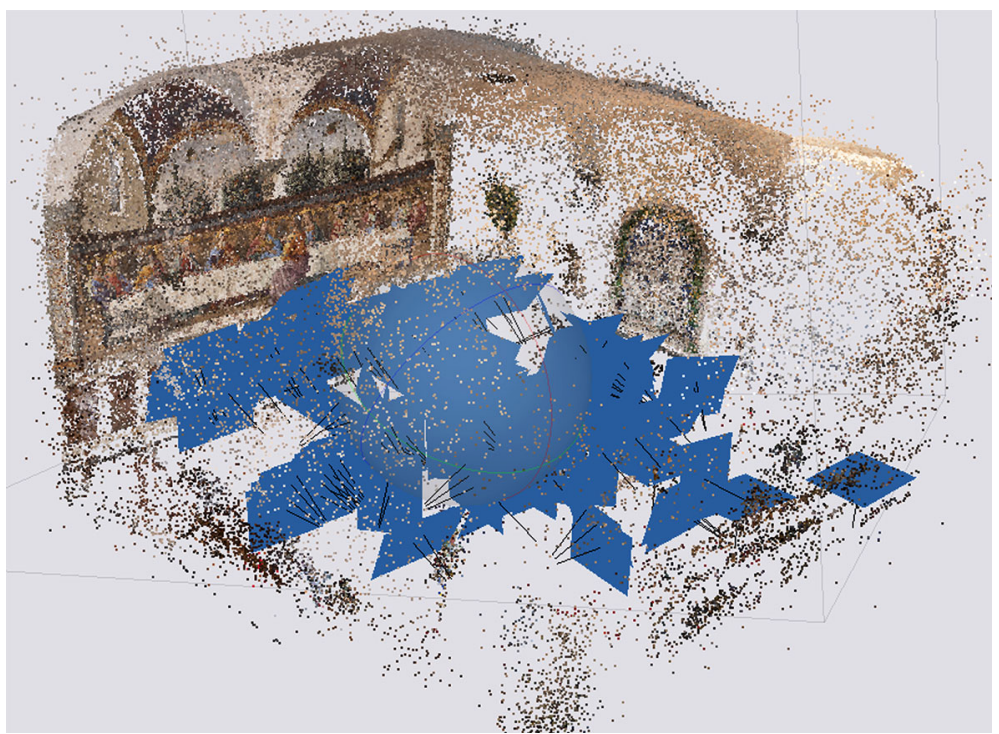

Fig. 3 San Marco's refectory: photographic survey and image processing. Image: authors

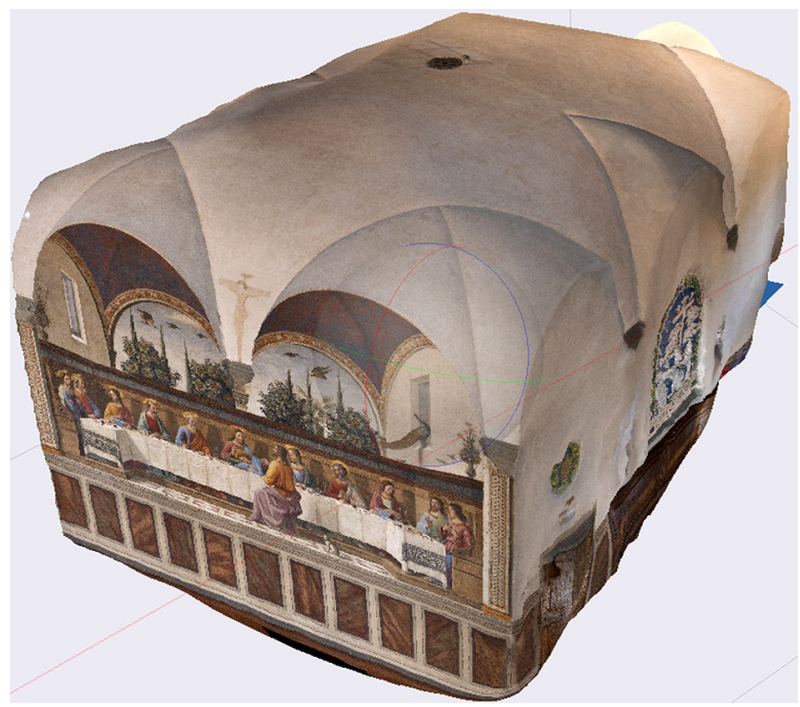

Fig. 4 San Marco's refectory: 3D model of the room with scaled painting mapped on the model. Image: authors

According to this hypothesis, the distance point given by the diagonals of the floor squares, is $8.10 \mathrm{~m}$. (ca. 14 braccia) away from the vanishing point. Consequently the position of the observer's viewpoint is $8.10 \mathrm{~m}$. away from the wall and $3.39 \mathrm{~m}$. (ca. 5-8/10 braccia) above the refectory floor. This viewpoint falls 


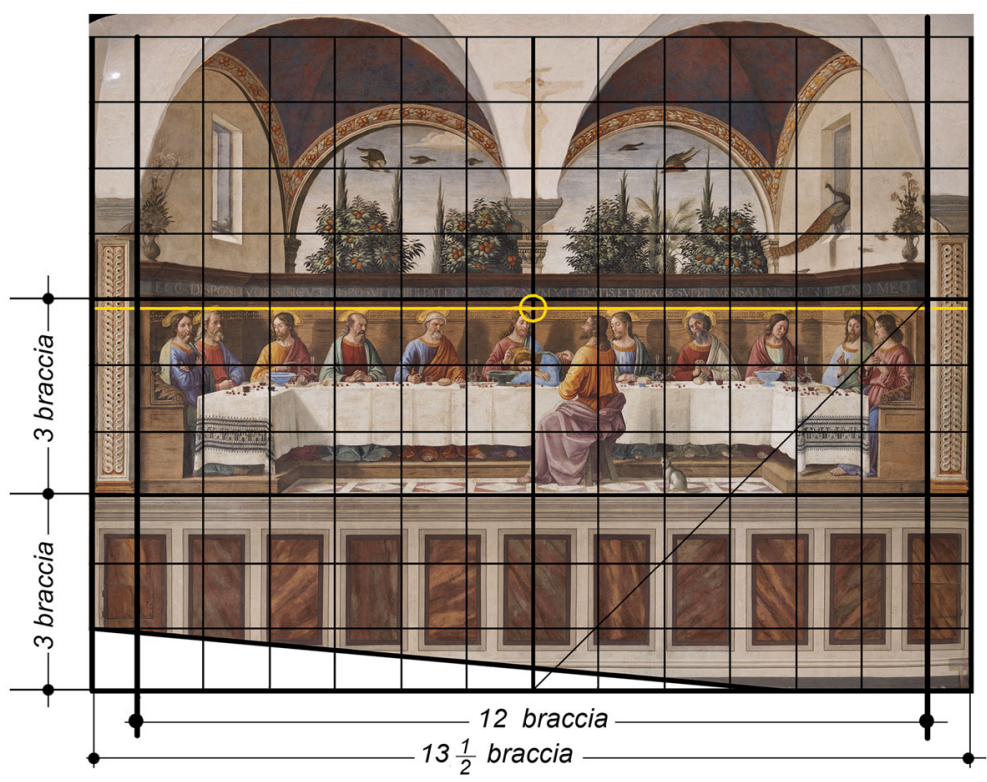

Fig. 5 San Marco's Last Supper with superimposed grid of $1 \times 1$ braccio. Image: authors
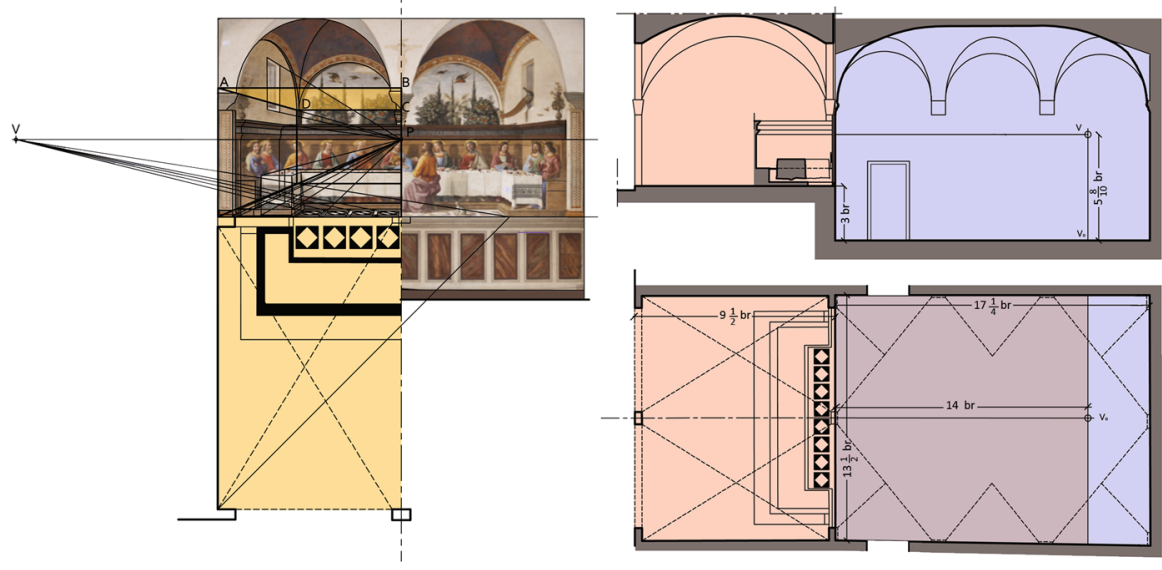

Fig. 6 San Marco: reconstruction of the virtual space: first hypothesis. Image: authors

inside the real space of the refectory itself, rather near to the back wall. The depth of the virtual loggia is close to $5.50 \mathrm{~m}(9-1 / 2$ braccia $)$. The long side of the mensa is $5.77 \mathrm{~m}$ and the short sides are $1.63 \mathrm{~m}$. The dimensions of the mensa width show some inconsistencies. The short sides both have a width of $58 \mathrm{~cm}$ while the long side seems to be $87 \mathrm{~cm}$ wide. The bench (whose short sides only are measurable) is $35 \mathrm{~cm}$ deep. 

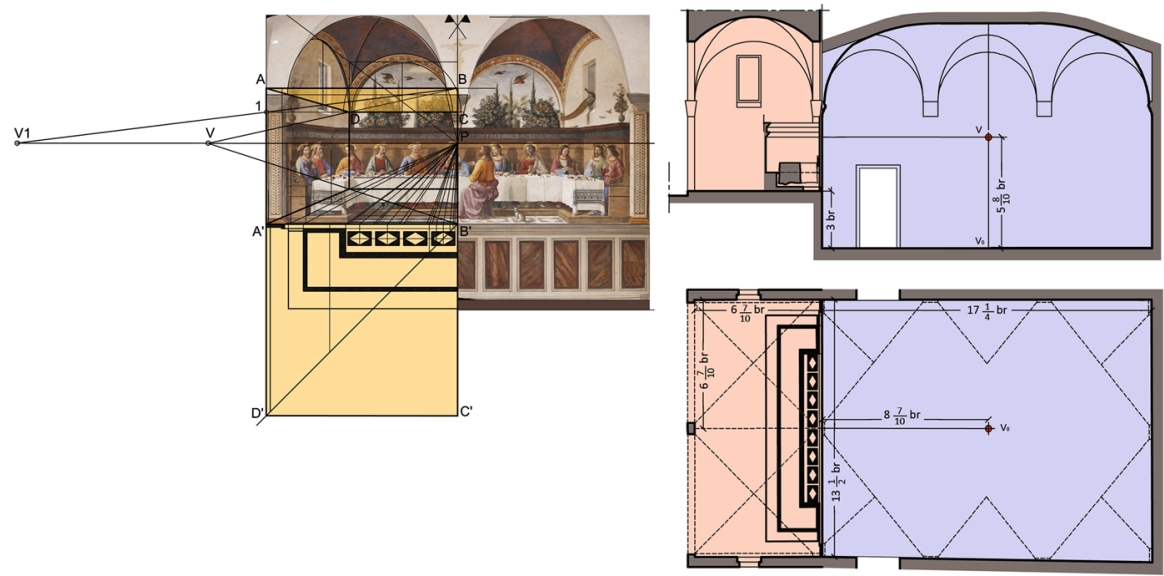

Fig. 7 San Marco: reconstruction of the virtual space: second hypothesis. Image: authors

\section{Second Hypothesis}

The square-being a "perfect" geometric figure according to Renaissance standards - may have subtended the design of the virtual loggia itself rather than the design of the mere floor decoration. Many porticoes and loggias, in Florence and throughout Italy, show a sequence of regular square bays covered with cross vaults or sail vaults, not least the portico of the Spedale degli Innocenti built in Florence by Brunelleschi around 1425, some fifty years before Ghirlandaio's frescos. In his De prospectiva pingendi, Piero della Francesca gives the rule on how to draw a perfect cross vault in perspective (Book II, theorem 11).

Following this second hypothesis (Fig. 7), and assuming that the two depicted vaults are square in plan, the depth of the loggia is equal to the width of one of its vaults and is thus measurable directly on the painting: $3.91 \mathrm{~m}$. The distance point given by the vault's diagonals is $5.07 \mathrm{~m}$ away from the vanishing point, consequently the viewpoint is $5.07 \mathrm{~m}$ from the wall and, again, $3.39 \mathrm{~m}$ above the floor. This time it falls exactly in the middle of the refectory. The long side of the mensa is $6.12 \mathrm{~m}(10-1 / 2$ braccia $)$ while the short sides are no more than $1.11 \mathrm{~m}$. (1$9 / 10$ braccia). The width of the table is roughly $60 \mathrm{~cm}$. on the long side, and $66 \mathrm{~cm}$. on the short sides.

\section{Discussion}

In both hypothesis the dimensions of the space and its furniture are realistic (Figs. 6, 7). Which case is the one that shows the best consistency between real and virtual space? We must admit that the room of the refectory does not have strong architectural features. It is rather small if we consider that it had to host many people all together. It is in fact known as "the small refectory" in contrast to the other room of the convent called "the big refectory". The two doors are located at 
two corners of the room, facing each other, very close to the painted wall. The rectangle of the plan does not have particular proportions such as the classical musical proportions that would be listed in the later treatises. The width of the room is $7.82 \mathrm{~m}$ (13-1/2 braccia ca.) and the length is $10.09 \mathrm{~m}$ (17-1/4 braccia ca.). The ceiling is a low rectangular cloister vault with lunettes on the four sides: two along the short sides and three along the long sides. However, this does not correspond to a precise $2: 3$ proportion to the room, since the lunettes have variable widths. The virtual painted cross vaults recall the corner lunettes of the refectory's ceiling. If we consider the second hypothesis in which the painted vaults are believed to be square, it could be that Ghirlandaio chose to visually expand the depth of the room by a distance roughly equal to the span of a lunette. Also, in the second hypothesis, the viewpoint falls exactly in the middle of the room, which may be either a striking coincidence or a deliberate choice.

Choosing between the two options is not the purpose of this paper. The motivations for any choice would be essentially subjective since we do not have any written or historical evidence to support one hypothesis rather than the other. But we may point out that the first hypothesis tends to show that there might be an emphasis, on behalf of the painter, on the biblical scene itself, that is, on the symbolic meaning of the fresco: on the figures who have a bigger mensa at their disposal. On the other hand, the second hypothesis would show a focus on the architectural design of the virtual space, in which furnishings and figures would have been more compressed, and the C-shape of the table and bench very shallow.

\section{Ognissanti}

As mentioned earlier, the Last Supper in Ognissanti (Fig. 8) is very similar to the one in San Marco. First of all its dimensions are very similar. The wall on which it is painted is 14 braccia wide and its maximum height at the top of the lunettes is 10-2/ 3 braccia ca. Just as in San Marco, the bottom of the painting is located at exactly 3 braccia above the floor. Once again Jesus and the Apostles are seated under a loggia composed of two cross vaults. The short sides of the loggia are closed by walls with a window in each, and the long side of the loggia is opened to an orchard in which many birds fly. This time however, the $\mathrm{C}$-shape mensa and the surrounding bench is much deeper. The furnishing is arranged in such a way that it occupies the full length and the full depth of the loggia, thus enclosing a deep rectangular space in the foreground. The depth of this space is enhanced by the floor decoration, which shows several rows of quadrangular tiles. But, even though the short sides of the mensa are obviously longer than in San Marco, only one Apostle is seated along each side, leaving a large empty space on the bench.

The analysis of the perspective image follows the same assumptions and criteria that we made earlier. According to the canons of Renaissance design, we assume that the floor decorated tiles and/or the vaults are square. This time the result of the analysis is strikingly different: the diagonals of the floor tiles and the diagonals of the vault bases all converge to the same vanishing point, proving that they are both simultaneously square in plan. The design of the virtual space here is perfectly 


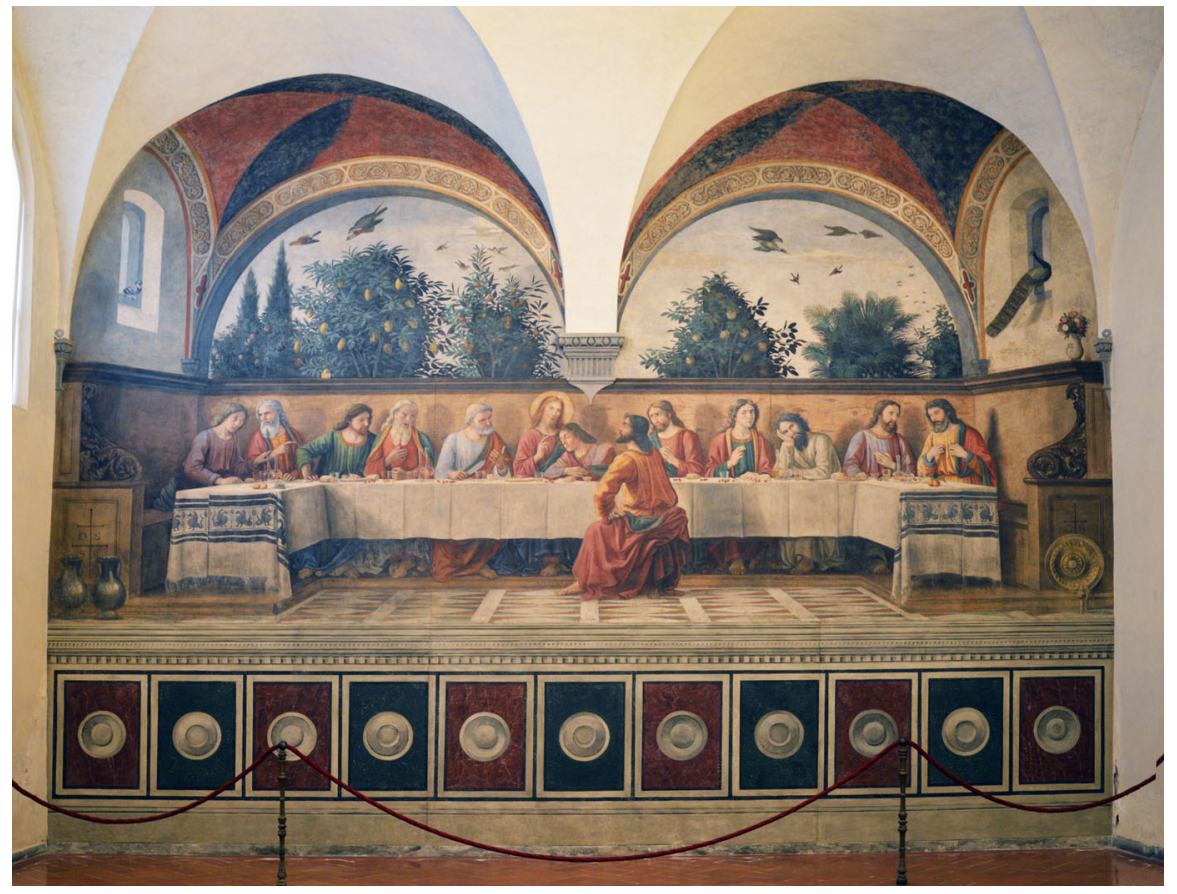

Fig. 8 Ghirlandaio. Last Supper in the convent of Ognissanti, Florence, 1482. Photo: authors

consistent: a loggia made of two square bays, whose floor is subdivided in square tiles, hosting a C-shape mensa that occupies the full depth and length of the available space. Simple and clear. The distance point is ca. $12.50 \mathrm{~m}$. (21-1/2 braccia) away from the vanishing point, thus the position of the virtual observer's viewpoint is $12.50 \mathrm{~m}$. away from the wall and $3.20 \mathrm{~m}$. high from the ground $(5-1 / 2$ braccia). This viewpoint falls inside the room, not as far as the middle of the refectory, but in the middle area. Let us see if this virtual space somehow related to the shape of the refectory itself (Figs. 8, 9, 10, 11).

In contrast with San Marco, the refectory in Ognissanti is a large room, narrow and very long, which has been carefully designed. Its dimensions are $8.16 \mathrm{~m}$. (14 braccia) by $32.84 \mathrm{~m}$. (56 braccia) which produces a perfect proportion of 1:4. The room has a single door in the middle of the short side that faces the painting. Visitors may thus see and admire the art piece from the moment they step into the room. Visitors enter in the refectory from a room known as the "lavabo room" which hosts a marble basin where the monks used to wash their hands before meals. The proportions of this room, whose length equals the width of the refectory, are $1: 2$, showing that the concern for beautiful proportions was not limited to the refectory only, but subtended the design of the whole convent. The refectory ceiling is a very elongated rectangular cloister vault with lunettes on the four sides: eight along the long sides and two along the short sides, all having the same dimension. The cross vaults of the painted loggia recall the corner lunettes of the room and their 


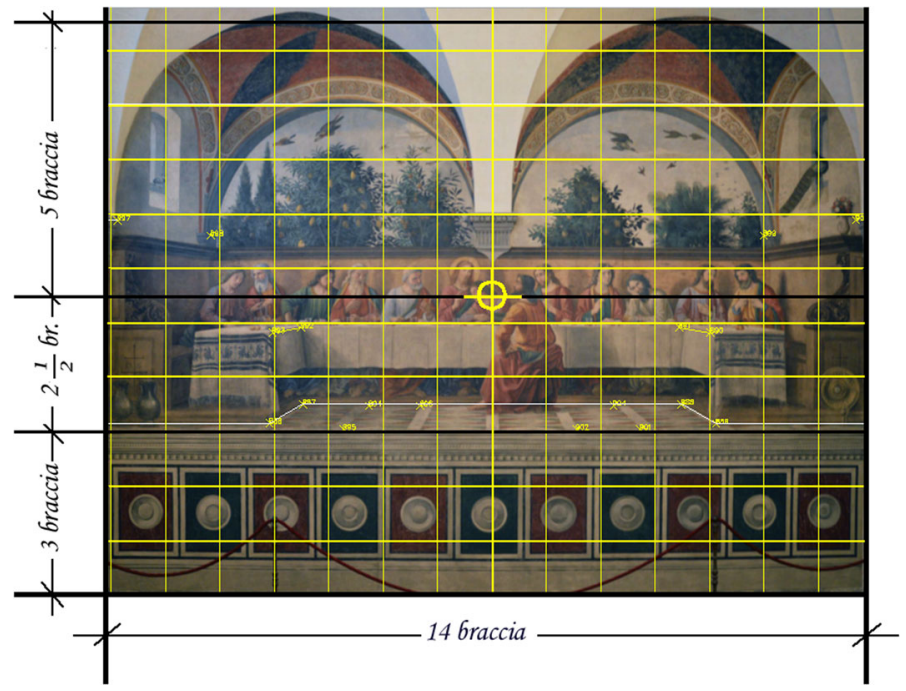

Fig. 9 Ognissanti's Last Supper with superimposed grid of $1 \times 1$ braccia. Image: authors

apparent depth, which is equal to half the width of the refectory (7 braccia ca.), matches the width of the lunettes.

Virtual space and real space are here closely related: Ghirlandaio clearly planned a visual extension of the refectory by one lunette span, painting a virtual space of proportions 1:2 that would transform the refectory's proportion in 2:9 (instead of $2: 8$ ). It is worth noticing that the painted loggia is similar in plan, extension and proportion, to the "lavabo room" which closes the refectory on the other side. The refectory is thus flanked by two equal spaces located on opposite sides: the entrance-real—and the "exit" to the garden of Eden—virtual.

\section{Trompe l'oeil Effects}

Trompe l'oeil is a French idiom, which has been internationally adopted. Art critics all use this idiom to refer to two different painting genres: either hyper-realistic still life paintings, so perfect that the viewer is deceived and takes for real the painted objects (fruits, insects, etc....), or full-scale architectural perspectives painted on walls that suggest openings to further spaces, rooms or gardens that do not exist in reality. Both artistic genres date back to classical antiquity. The ancient Greek legend of Zeuxis and Parrhasius (early fifth century B.C. circa) related by Pliny the Elder (The Natural History 35.36) recounts a competition between two painters both aiming at hyper-realism. The first artist succeeded in deceiving birds that came to pick the grapes that he had painted, and the later deceived no less than his fellow painter who tried to pull out curtains that he had depicted on the wall. Similar to these legendary art works, ancient instances of architectural trompe l'oeil are preserved in several Pompeian and Roman villas, showing fake gardens seen through fake openings on interior walls. Not surprisingly the art of perspectival 

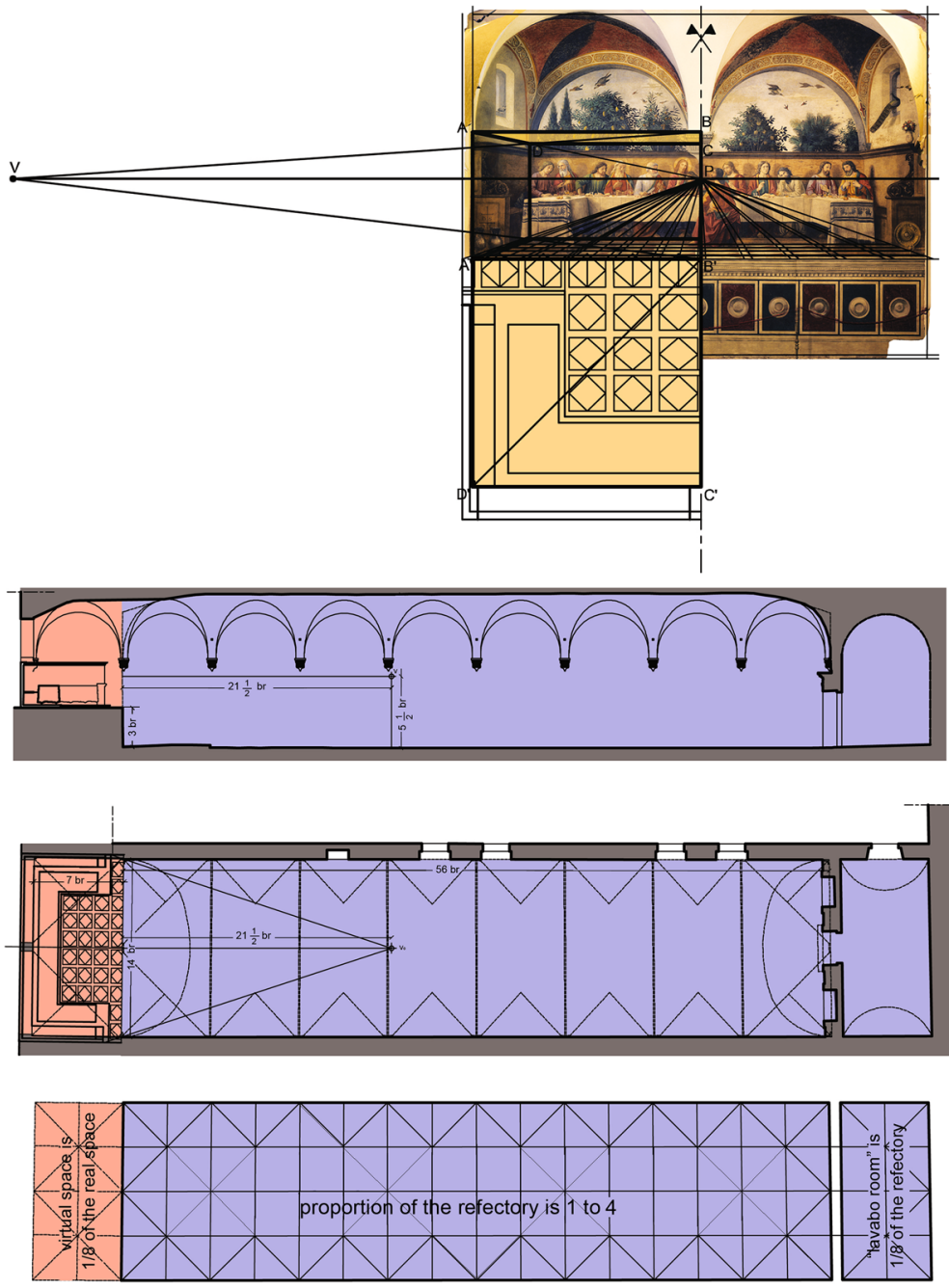

Fig. 10 Ognissanti: reconstruction of the virtual space and relationship with the real space. Image: authors

illusionism recurred in the Renaissance, and would flourish in the Baroque period, as a consequence of the progress achieved in perspective science.

Can Ghirlandaio's Last Supper frescoes be considered as early Renaissance trompe l'oeil? If we take for granted its realistic genre and its artistic quality, a full-scale architectural perspective can be considered as an actual trompe l'oeil under two conditions. First the viewpoint of the virtual observer must be located in a position, and at a height that is indeed reachable by a human eye, otherwise the illusion will not be produced in the mind of the users of the rooms in which the painting stands. Second, the apparent size of all figures and all objects receding in the virtual space must be calculated and represented according to their natural full size. 


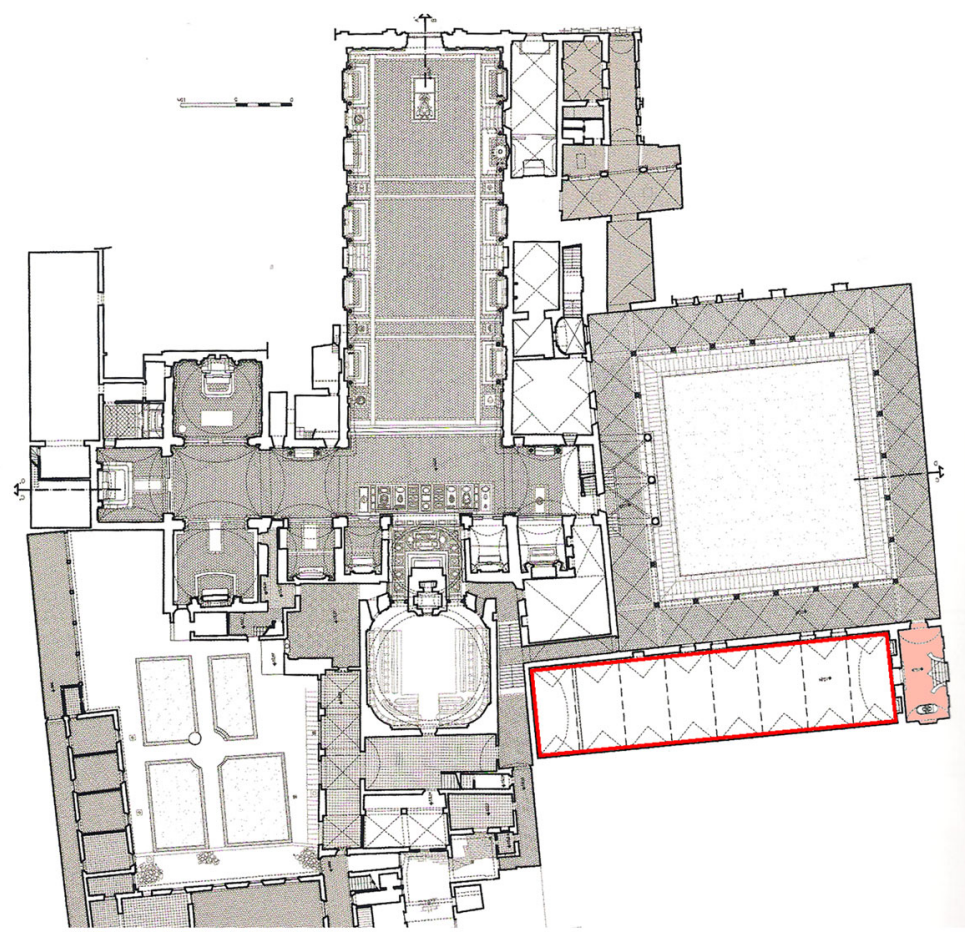

Fig. 11 Ognissanti: plan of part of the convent. Image: authors, after (Bartoli 2011)

Consequently, given these two conditions, Ghirlandaio's Last Supper depictions are not trompe l'oeil. In fact, even if the architecture, furnishings and figures are apparently at full scale, following the medieval tradition for such biblical representations, the frescoes are located in an elevated position from the floor. Is this choice dictated by a wish to express humility, symbolic reasons, or practical necessities? We may only guess. It may be that the monks and priests dining in a refectory did not dare place themselves at the same level of Jesus and the Apostles, but would feel inferior, therefore at a lower level. It may be that, since the Gospels by Mark (14.15) and Luke (22. 1 2) relate that the Passover Supper took place in a "large upper room", then the depiction of the scene had to in some way indicate this detail, and be located in an upper position respect to the floor of the room in which it stood. Alternately, it may be that if the painting had been placed at floor level in the refectory, it simply could not have been seen properly by all the monks dining together, since the closest ones would hide it from their brothers seated farther away. Whatever the motivation, Last Supper depictions-before and after Ghirlandaio-were usually placed at a height of three braccia above the floor. And since the horizon line and vanishing point were close to the eye level of the figures of the painting, this put them at an inaccessible height for any viewer seated or even standing in the room. If Ghirlandaio (or his later fellow painters such as Perugino, Leonardo, and others.) intended to suggest a theatrical show taking place 
on a raised stage that the audience would see from beneath, then the horizon line and the vanishing point should have been placed at a lower height, closer to the bottom of the fresco and thus closer to the height of a person standing in the room. Such an uncommon setting would not have been totally innovative in the history of early perspective. There are examples of scenes intentionally seen from beneath which had been painted prior to Ghirlandaio. We can mention the Trinità: a small fresco painted by Masaccio around 1427 on a wall of Santa Maria Novella in Florence, in which the vanishing point coincides with the base of the fake elevated chapel. Two works by Piero della Francesca himself show a perspective view in which the vanishing point is very low: The Meeting of Solomon and the Queen of Sheba (1452), a fresco in the church of San Francesco in Arezzo, and the later small painting of The Flagellation of Christ (1460 ca.) which shows a much more elaborated perspective construction than the previous one. In the Flagellation the horizon line is very close to the floor, much below the eye level of any figure present on the picture (Fig. 12). However, the painting is nowadays kept in a museum and no one knows for sure where it was originally meant to be hung; therefore the motivation for the view from beneath is yet unexplained. Because of its small dimensions it cannot be considered as a trompe l'oeil.

Ghirlandaio prepared his pictures as if they had to be seen frontally. If a platform was built in the refectory at a proper distance and a proper height, providing the correct viewpoint for visitors, then the fresco would indeed appear as a true trompe l'oeil.

Another important issue to keep in mind while analyzing the frescoes is the relationship between what we call today "the vanishing point" and the eye of the observer, as it was understood by the pioneers of Renaissance perspective.

From his text On Painting (Alberti 1990), we know that Alberti establishes a loose relationship between the latter and the former. He explains at length how the visual rays that connect the edges and surfaces of the physical bodies to the eye of the observer form a pyramid and how the "centric ray" is the average middle ray that strikes the object producing two similar angles on both sides. This suggests that each object has its own centric ray. However, for the perspective construction of an architectural space composed of many objects, Alberti considers a single average centric ray which produces a single "centric point" on the picture plane, since the perspective image stems from a cross-section of the visual pyramid on a certain plane according to a given distance. While explaining the first steps of perspective drawing, he says:

I establish a point in the rectangle wherever I wish; and as it occupies the place where the centric ray strikes, I shall call this the centric point. The suitable position for this centric point is no higher from the base line than the height of the man to be represented in the painting... (Alberti 1990: 54).

Therefore, for Alberti, the "centric point", which we know today as the "vanishing point" (in a one-point perspective), is related to the height of a standing man whose feet are on the ground line, not to his eyes, and there is a certain margin of freedom in choosing its position. 


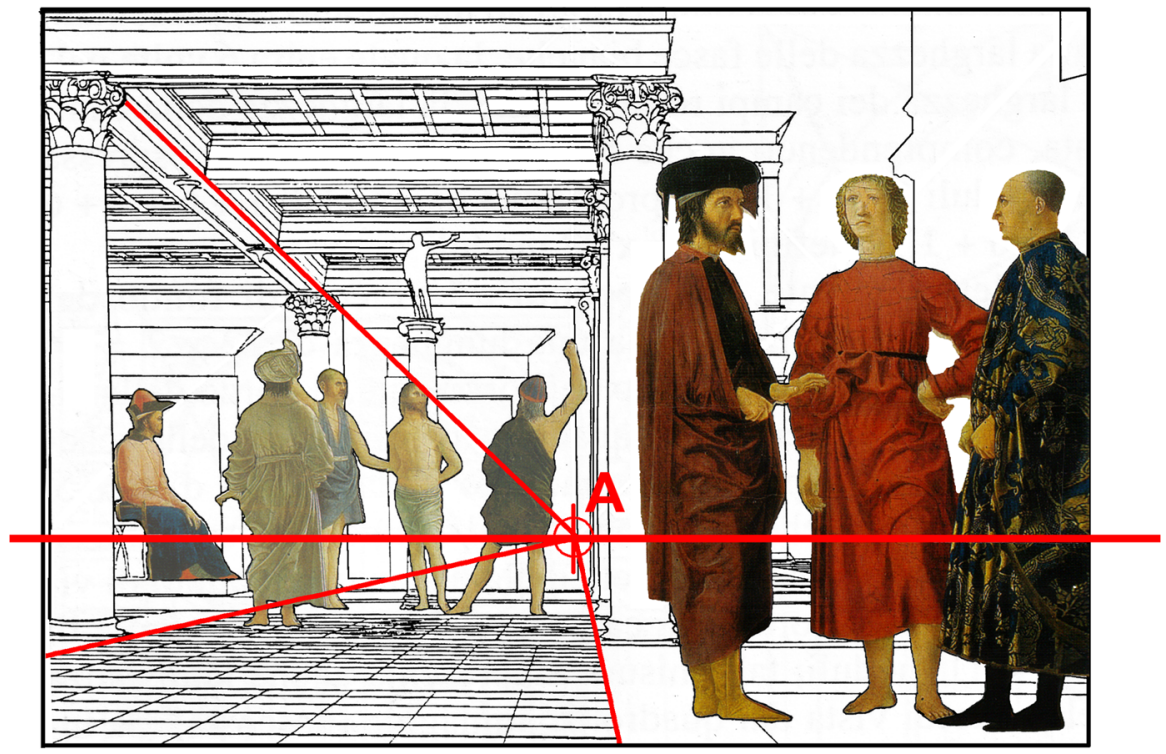

Fig. 12 Drawing from The Flagellation of Christ by Piero della Francesca, 1460 ca (before 1475), showing the position of the vanishing point. Image: authors

The relationship between vanishing point and eye of the observer is clearly stated in Piero della Francesca's De prospectiva pingendi. In all the figures of this treaty, lines converge to point " $A$ " which is the eye of the observer. However, Piero is a mathematician and addresses the question of perspective from a very theoretical standpoint. Like the ancient treatise on Optics by Euclid, Piero's book is a series of mathematical theorems that he demonstrates and illustrates. Vanishing point and distance point are two abstract mathematical entities, and Piero is primarily interested in the proportional ratios that are produced by the optical foreshortenings occurring from a certain distance to a given plane. The actual position of the viewer's eye in a precise space, and its relation with the various parts of this space, is nowhere discussed. Unlike Alberti, Piero does not give advices on how to start a painting. He gives the solution to several exercises such as "draw an octagonal well in perspective", or "draw a rotated pentagon in perspective". Each time point "A" is given, but its meaning is not discussed.

In Ghirlandaio's frescoes the vanishing point is "centric" in the sense that it located precisely at mid-width of the painting. It is not three braccia high from the virtual floor, as recommended by Alberti but is lower: 2-8/10 braccia in San Marco, 2-1/2 braccia in Ognissanti. It is close to the eye-level of Jesus and the Apostles but does not exactly match it: in San Marco it is a little bit higher (just at the top of the heads), in Ognissanti it is a bit lower. Why this is so, we cannot know for sure. Either Ghirlandaio followed Alberti's approximate rule "wherever I wish", or he followed Piero della Francesca and was aware of the precise relationship between the vanishing point and a compulsory point of projection-the eye of the observer. In the second case it would seem that the viewer does not dare to stare directly in the 
eye of Jesus. This particular "eye to eye" relationship between Jesus and the hypothetical viewer would only be later imagined by Leonardo while painting his famous Last Supper on the wall of Santa Maria delle Grazie in Milan.

A final remark about the search for trompe l'oeil effects regards the reliability of the loggia structure. The two virtual vaults are actually supported by a wall whose presence is meant to disappear with the illusionary perspective, and the wall has not be replaced by the necessary column that should be there to support the ceiling. Of course a fake column in the exact middle of the fresco would have been a serious problem for the painter, since Jesus is traditionally seated in the middle of the mensa, in the centre of the representation. Hiding anybody or anything behind a column does not seem to have been an option, and-on this point-Ghirlandaio does not break the medieval rule, and displays a series of portraits behind a mensa in a space which is totally open towards the room. Such detail underlines how advancements in art come step by step: Ghirlandaio is an innovator but not a revolutionary.

The very first perfect trompe l'oeil in art and architecture history would be the depiction of the fake choir of Santa Maria presso San Satiro in Milan, done by Donato Bramante somewhere between 1480 and 1486. This artwork, nearly contemporary to Ghirlandaio's frescoes in San Marco and Ognissanti, shows how quickly progress was made in perspective science, and how quickly the innovative experimentations done by various artists produced new applications, with smallscale and large-scale perspective representations. Bramante was the first artist to depict a fake architecture that has to be seen from a precise standpoint (close to the entrance of the church) in order to produce the perfect illusion in the eye of a viewer standing on the floor of the church nave (Mele and Giampiero 2012). However Bramante, in this work, did not address the question of representing figures in the virtual space.

\section{Concluding Remarks}

Our present analysis of Ghirlandaio's two Last Supper depictions relies on a modern scientific approach, based on measurements with electronic devices, which might seem inappropriate with respect to the knowledge of the years in which the frescoes were produced. Nonetheless the results of the inquiries show how precise and up-todate the mathematical constructions were. Our demand for exactness is not disappointed. The inaccuracies and inconsistencies of some measured objects-for instance the width of the table that differs between the long side and the short sides-may be due to adjustments (deliberate or not) made in the painting phase subsequent to the drawing phase. Slightly enlarging the apparent depth of the table in order to provide a more visible base for the glasses and dishes could come from a purely visual and artistic necessity, but certainly does not compromise the overall beauty of the painting.

The comparison between San Marco and Ognissanti suggests a few remarks. It seems clear that the trompe l'oeil effect in Ognissanti is more controlled and planned than in San Marco. The virtual space is more carefully calculated, with a 
great coherence between the various architectural features $(3 \mathrm{D}$ shapes and 2D floor decoration) and furniture design. Further, it is indisputably strongly related to the features of the real space. This coherence was probably easier to achieve in a refectory whose architectural qualities are more evident than in San Marco: precise classical proportions of the room and regularity of the lunettes of the vault. When the starting pattern is clear, designing a continuity means playing with the given rules. When the initial rules are not clear, the game is loose.

This observation tends to confirm the recent chronological conclusions by art historians who dated the Ognissanti fresco after the one in San Marco (Acidini Luchinat and Proto Pisani 1997). Their statement comes from the comparison of the figures - the Apostles-who are less stiff in Ognissanti, seated in a less upright position, showing greater movements and more passion than those in in San Marco. We can affirm that the progress in depicting the emotional states of the Apostles, goes in parallel with the progress in the use of the expressive potentiality of perspective and the use of its capacity to produce accurate trompe l'oeil effects that will enhance the sense of drama in the mind of the viewers.

Acknowledgements Sylvie Duvernoy is the author of $\S \S 1,4,5,6$. Giampiero Mele is the author of $\S \S 1$, 2, 3, 6. Authors would like to express their sincere gratitude to the museum directors, Ms. Magnolia Scudieri and Ms. Monica Bietti, from the Polo Museale Fiorentino, for their permission to carry on survey operations in the convents of San Marco and Ognissanti.

\section{References}

Alberti, Leon Battista. 1991. On Painting. Martin Kemp, ed. London: Penguin.

Acidini Luchinat, Cristina, Rosanna Caterina Proto Pisani, eds. 1997. La Tradizione Fiorentina dei Cenacoli. Firenze: Cassa di Risparmio di Firenze.

Bartoli, Maria Teresa. 2011. Dal Gotico Oltre la Maniera, gli Architetti di Ognissanti a Firenze. Firenze: Edifir.

Mele, Giampiero. 2012. "Santa Maria delle Grazie e Cenacolo Vinciano" and "Santa Maria presso San Satiro" in Milano, Maths in the City. Sant'Arcangelo di Romagna (RN): Maggioli.

Piero della Francesca. 1984. De prospectiva pingendi (ca. 1482), ed. Giusta Nicco-Fasola. Firenze: Le Lettere.

Sylvie Duvernoy holds a Master Degree in architecture from the University of Paris, France, and a Ph.D. in architecture from the University of Florence, Italy. Besides running a private office with three partners, she has been teaching architectural representation ever since the beginning of her post-doc studies, and is currently adjunct professor at the Design School of the Politecnico di Milano. She is involved in research programs focusing on representation issues, and history of representation. She is actually the contributing editor of the Nexus Network Journal for book reviews.

Giampiero Mele holds a Master Degree in architecture, and a Ph.D. in architecture from the University of Florence, Italy, and a Ph.D. in "Architectural and Urban Design" from the University of Paris. He is an associate professor at the Università Telematica Uniecampus, and adjunct professor at the Design School of the Politecnico di Milano. His fields of research are the relationships between geometry and arithmetic in historic architecture, and drawing in architecture and design. The results of his studies were published and communicated in several international meetings and journals. 